\title{
Entre o não lugar e o protagonismo: articulações teóricas entre trabalho, gênero e raça
}

\author{
Elisabete Figueroa dos Santos ${ }^{1}$, Maria Fernanda Diogo ${ }^{2}$, Lia Vainer Shucman ${ }^{3}$ \\ Universidade Federal de São Carlos (São Carlos, SP), Universidade Federal de Santa \\ Catarina (Florianópolis, SC), Universidade de São Paulo (São Paulo, SP)
}

\begin{abstract}
Este artigo tem como objetivo analisar o entrelaçamento das categorias trabalho, gênero e raça, visibilizando os arranjos sociais responsáveis pela criação de um não lugar destinado a mulheres, negros e, particularmente, às mulheres negras. Para cumprir esta finalidade utilizamos dados quantitativos e qualitativos produzidos por institutos de pesquisas brasileiros e por pesquisadores da temática étnico-racial. A análise desses indicadores sociais reitera que o ambiente do trabalho é um espaço adverso à diversidade. Percebe-se haver um reforçamento mútuo entre o racismo e o sexismo na medida em que se nota a existência de um cenário em que grupos não-dominantes parecem circular por territórios de outrem. Assim, gênero e raça são variáveis que interagem produzindo oportunidades desiguais para sujeitos diferentes. Diante dessa realidade, buscou-se destacar algumas formas como os grupos marginalizados tecem estratégias de enfrentamento para superar as discriminações, afinal não se deve apressar juízos que atrelem esses atores ao local da aceitação e da passividade. Apontamos, contudo, que uma análise consistente deve partir da realidade dos grupos, fugindo de generalizações precipitadas e sem incorrer em um raciocínio "se, logo", que atrele necessariamente desigualdade a enfrentamento. Ressaltamos a importância da ação de movimentos sociais antirracistas e antissexistas bem como de Políticas Públicas que promovam a igualdade racial e de gênero.
\end{abstract}

Palavras-chave: Trabalho, Gênero, Raça, Desigualdade, Enfrentamento.

Between displacement and protagonism: theoretical articulations between work, gender and race

This papers aimed to analyze the intertwining of three categories: work, gender and race, exposing, through quantitative and qualitative data produced by researchers of racial thematic, the social arrangements that are responsible for the creation of a displacement or non-placement of women, Black and, especially, Black women as social actors in the workplace. The analysis of social indicators reaffirms that the work environment is not complacent to diversity. Differences in relation to the "pattern" individual - that is, White males - generate subaltern conditions in work insertion and in day-to-day dealings. We noted that there is a mutual reinforcement between racism and sexism, in the sense that there is a synergy between ethnic-racial domination and gender domination. This creates a scene in which nondominant groups seem to be circulating in territories belonging to other individuals, therefore, being displaced as actors. This to say that gender and race are elements that interact, producing unequal opportunities to different individuals. We intended to point out some strategies created by marginalized groups to fight discrimination, since we should not assume that these actors are necessarily passive and receptive to their given condition. Beyond the personal and collective strategies to confront discrimination, it is important to point out the indispensable role of anti-racist and anti-sexist social movements, as well as the role of public policies that promote race and gender equality in this matter.

Keywords: Work, Gender, Race, Inequality, Coping.

\section{Introdução}

s Ciências Humanas costumeiramente tecem suas teotid conceituais a partir de uma perspectiva tida como unito
-heterossexual-civilizado-do-Primeiro-Mundo", ignorando aqueles/a
de referência (Rago, 2000, p. 25). Esse viés, contudo, tem sido p
1 Doutoranda em Psicologia pela Universidade Federal de São Carlos, Bolsista FAPESP.
2 Doutora em Psicologia pela Universidade Federal de Santa Catarina.
3 Pós Doutoranda em Psicologia Social pela Universidade de São Paulo, Bolsista Fapesp. 
xeque, de modo a suscitar estudos preocupados em tratar daqueles que diferem desse sujeito da norma, apontando as repercussões das diferenças nos casos específicos bem como colocando a própria norma em xeque. A temática proposta neste artigo busca justamente lançar luzes nas fissuras desse modelo, entrelaçando as categorias trabalho, gênero e raça ${ }^{4}$.

O trabalho foi tomado como a atividade que define o ser social, sendo o ato laboral responsável pela modificação do meio e do sujeito que o executa. Trata-se de uma categoria central não apenas para aqueles que estão formalmente inseridos no mundo de trabalho, com vínculos estáveis, boas ocupações e salários razoáveis, mas também para os que se encontram em ocupações informais, instáveis, subempregos, com baixas remunerações etc. A precariedade da inserção no trabalho gera impactos negativos nas formas como os sujeitos representam o mundo, se representam no mundo e atuam sobre ele. Em outras palavras, a precarização das relações de trabalho atua negativamente sobre a identidade do trabalhador (Santos, 2011).

De acordo com Bento (2002), as relações hierárquicas, prósperas para as práticas discriminatórias, encontram espaço privilegiado nas relações de trabalho. Segundo esta autora, as decisões tomadas nesse setor influenciam fortemente a inserção social dos diferentes segmentos e a possibilidade ou não de mudança no quadro das discriminações.

Gênero e raça são variáveis que interagem produzindo diferentes lugares para os diferentes sujeitos, dadas suas características, de modo a resultar em oportunidades desiguais para sujeitos diferentes. Verifica-se que as configurações produzidas pelo modo como essas variáveis se interceptam atualmente guarda traços das relações desenvolvidas no regime escravocrata, preservando a associação do homem branco com a imagem do senhor, sujeito por excelência e da mulher negra com a imagem da escrava, numa categoria subumana, como propriedade e força de trabalho.

Raça e gênero, categorias sociológicas, são essenciais para a compreensão das relações sociais cotidianas. As ideias de raça e de gênero estão presentes em diferentes experiências da vida social: nas distribuições de recursos e poder, nas experiências subjetivas, nas identidades coletivas, nas formas culturais e nos sistemas de significação. No cotidiano brasileiro, raça e gênero sedimentam e estruturam não só desigualdades socioeconômicas, mas também simbólicas e culturais, relativas às mulheres e aos negros.

Estudos nacionais e internacionais apontam o racismo e o sexismo como a explicação mais sólida para as desigualdades socioeconômicas no Brasil (Hasenbalg, 1979; Guimarães, 1999; Andrews, 1998; Skidmore, 1976; Telles, 2003; Bento \& Carone, 2002; Yannoulas, 2002; Barros, Corseuil, Santos \& Firpo, 2001; entre outros). O contexto sexista e racista brasileiro propicia mediações bastante diferenciadas para a constituição de sujeitos. A marca dessas desigualdades perpassa todo o campo social: a casa, a escola, o bairro e os espaços públicos são marcados pela supervalorização do homem branco heterossexual em detrimento de outras identidades. A inserção ou não no mercado de trabalho, a quantidade de horas trabalhadas, as posições sociais que se ocupa e o acesso às previdências sociais acompanham tais desigualdades (Schucman, 2012).

Discriminações diretas e indiretas são as diferentes facetas da interação entre gênero e raça. Discriminação direta está relacionada à interferência no trânsito dos trabalhadores e trabalhadoras no mercado de trabalho, das posições e áreas de trabalho, dos salários recebidos e jornadas verificadas para as minorias 5 . Já a expressão indireta é relativa às discriminações sofridas fora do

4 O conceito de "raça" usado neste trabalho é o de "raça social", apoiado em Guimarães (1999), significando "construtos sociais, formas de identidade baseadas numa ideia biológica errônea, mas eficaz socialmente, para construir, manter e reproduzir diferenças e privilégios" (p. 153). Para esse autor, se a existência de raças humanas não encontra qualquer comprovação no bojo das ciências biológicas, elas são, contudo, "plenamente existentes no mundo social, produtos de formas de classificar e de identificar que orientam as ações dos seres humanos" (p. 153).

5 Utilizamos a ideia de maioria e minoria não em termos numéricos, mas em termos de relações de poder. O termo maioria se refere a qualquer grupo de pessoas que controle a maior parte dos recursos econômicos, de status ou de poder, estabelecendo relações 
mercado de trabalho, acerca das credenciais educacionais e demais qualificações que também resultam em desigualdades.

Percebe-se haver um reforçamento mútuo entre o racismo e o sexismo na medida em que ocorre uma potencialização entre a dominação étnico-racial e a dominação de gênero, de modo que se cria um cenário em que grupos não-dominantes parecem circular pelos territórios de outrem (Anjos, 2004). Quando comparamos homens e mulheres, brancos/as e negros/as, em termos de condições de inserção e ocupação de cargos no mercado de trabalho, cabe discernir os pesos relativos aos efeitos da inscrição racial e das relações de gênero, tarefa que tem sido meta de muitos estudos (ver Bento, 1995, 2000; Dieese, 2005; Paixão \& Gomes, 2008; Soares, 2000; Lombardi, 2010; Bruschini, 2007; Araújo \& Scalon, 2005; Yannoulas, 2002), contudo ainda bastante árdua devido às nuances e artimanhas da discriminação.

Às mulheres brasileiras se atribui maior taxa de escolaridade, contudo, os postos de trabalho e os respectivos rendimentos estão aquém dos percebidos pelos homens. Se compararmos homens brancos e mulheres negras, observaremos a existência de um enorme abismo entre as ocupações e os rendimentos experimentados por ambos, estando a mulher negra em uma evidente desvantagem. Contudo, quando comparamos as mulheres brancas e os homens negros verificamos que elas apresentam, de modo geral, melhores ocupações e salários que eles. Pode-se afirmar que a capacidade de acesso ao capital, seja financeiro ou intelectual, encontra-se vinculada aos graus de acesso em função de distintas inscrições de gênero e de raça. Esses diferenciais podem ser explicados pelas formas como as relações de gênero e as raciais interagem dentro e fora do mercado de trabalho.

O objetivo deste artigo, justamente, encontra-se em analisar o entrelaçamento das categorias trabalho, gênero e raça, discutindo os arranjos sociais responsáveis pela criação de um não lugar destinado a mulheres, negros/as e, particularmente, às mulheres negras, buscando-se pontuar as formas como os grupos marginalizados tecem estratégias de enfrentamento para superar as adversidades.

\section{Entrelaçando trabalho, gênero e raça}

O mundo do trabalho tem sofrido intensas transformações. Segundo Araújo, Amorim e Ferreira (2004), essas transformações, associadas às mudanças de base técnica e à difusão, em escala global, de novos paradigmas de gestão e organização da produção e do trabalho, ficaram conhecidas no Brasil com o nome de reestruturação produtiva. Para estas autoras, esse processo se originou na indústria, buscando qualidade e flexibilização a baixos custos, mas se expandiu para os mais distintos setores da economia, incluindo vários segmentos do setor de serviços. As práticas de sobrevivência empresarial desembocaram no fenômeno da flexibilização, da informalidade, no desmantelamento da proteção social e no aprofundamento das desigualdades sociais. Predomina a lógica da "liofilização organizacional" (Antunes, 2005, p. 50), movimento caracterizado pela contração do trabalho estável e regulado, substituição crescente de trabalhadores/as por maquinário tecnocientífico, ampliação das formas desregulamentadas de trabalho precarizado, atípico (terceirizados, quarteirizados, subcontratados, part time), ampliação da exploração da dimensão subjetiva do/a trabalhador/a etc. Segundo Araújo (2008, p. 54), o/a trabalhador/a raramente é considerado/a sujeito neste contexto, restando-lhe o lugar de executor de tarefas. "Ele[a] não passa de 'força de trabalho', de 'recurso humano', sempre reificado[a], gerido[a] como coisa, como qualquer outro instrumento ou máquina a serviço da produção, da acumulação ou do lucro”.

injustas com as minorias sociais (Roso et al., 2002; Moscovici, 2000). 
Nessa perspectiva, o trabalho deixou de ser um direito para se transformar em um recurso destinado a assegurar a rentabilidade, e o/a trabalhador/a passou a ser um custo a ser reduzido. Homens e mulheres foram solapados pelas transformações em tela, contudo pesquisadoras e pesquisadores são incansáveis em apontar que o emprego feminino recrudesce em maior escala nas situações de crise. Em geral, prevalece a segregação laboral, menor rendimento pago às mulheres, maiores taxas de desemprego, dupla jornada de trabalho e aumento da presença feminina em ocupações precárias (Lombardi, 2010; Bruschini, 2007; Araújo \& Scalon, 2005; Hirata, 2002, 2010; Yannoulas, 2002, entre outras autoras).

A categoria gênero surgiu em substituição ao termo sexo, pois este produzia entendimentos fundados somente no biológico. Conforme Fonseca (2000, p. 103) “... ninguém se faz homem ou mulher apenas pelo fato de ter nascido macho ou fêmea, as identidades subjetivas são masculinizadas e feminizadas a partir de longos processos de inculcação e socialização". Gênero transcende o corpo e se inscreve nas relações sociais estabelecidas nas instituições, nas estruturas, nas práticas cotidianas etc.

De modo geral, observa-se que os jogos de poder entre homens e mulheres estão longe do equilíbrio, ocorrendo uma dominância histórica do masculino sobre o feminino. Fávero (2010) aponta para uma concepção dualista, de herança grega, inocentada pela naturalização das diferenças, que opõe homens e mulheres, impregna-se na linguagem cotidiana produzindo e reproduzindo estereótipos do tipo "a mulher é mais amável, o homem é mais bruto"; "a mulher chora à toa, o homem é mais racional”.

No caso das desigualdades de raça, os privilégios que os/as brancos/as recebem em relação aos/às negros/as já foram interpretados por diferentes discursos sociológicos como um fator relacionado à condição de classe - ainda que não se esgote nessa esfera - em que os/as negros/ as foram inseridos após o regime escravagista. Contudo, estudos sobre as desigualdades raciais iniciados nos anos 1970, por Hasenbalg (1979), demonstram como o racismo no Brasil faz que esta estrutura de desigualdade racial se perpetue.

O autor aponta falhas tanto na teoria marxista sobre a questão racial quanto nas teorias coloniais, demonstrando que a primeira não dá conta de explicar o racismo entre as classes baixas e fora das estruturas de classes, e a segunda, a teoria colonial, não explica a exploração de classe ou as relações entre estrutura e dominação de classes, opressão e estratificações raciais. Para preencher essa lacuna nas duas interpretações, Hasenbalg (1979) postula que a opressão racial beneficiaria não somente os capitalistas brancos como também a população branca que não detém os meios de produção. Para o autor, a maioria dos brancos/as teria vantagens na opressão racial e no racismo, pois esses mecanismos se traduziriam em vantagens no preenchimento de posições na estrutura de classes, redundando em privilégios materiais e simbólicos. Além disso, os brancos também teriam prerrogativas menos concretas, contudo fundamentais ao sentimento e à constituição da identidade dos sujeitos, tais como a honra, o status, a dignidade e o direito à autodeterminação.

Outro ponto importante para os estudos raciais é a análise de Hasenbalg (1979) sobre a escravidão no Brasil. Este autor critica as perspectivas teóricas que estabelecem uma ligação causal e direta entre o passado escravista e a situação da população negra pós-abolição, que "anormalizaram" os/as negros/as, resultando na "cultura de pobreza". Para tal autor, este tipo de análise leva a um nó impossível de desatar, já que implica encarar a pobreza como causa de si própria e não como efeito do racismo.

6 Hasenbalg (1979) contraria Florestan Fernandes com essa colocação. Florestan justificou a não entrada dos/as negros/as no sistema capitalista, depois de abolida a escravidão, pelo fato que eles/as, por causa do sistema escravagista, haviam ficado desestruturados como família e no aspecto moral. Essa teorização culpabiliza os/as negros/as e desvia o foco central do racismo. 


\section{Entrelaçando trabalho e gênero}

Classicamente pesquisas sobre o setor produtivo focavam a classe trabalhadora como um segmento uníssono. Elizabeth de Souza-Lobo, ao apontar que as condições de negociação da força de trabalho masculina e feminina não eram iguais, assinalando sua exploração de forma sexuada, foi uma das pioneiras no Brasil a lançar-se à denúncia das desigualdades de gênero no mundo do trabalho (Souza-Lobo, 1991). No exterior, um marco para os estudos de gênero no trabalho é o GEDISST ${ }^{7}$, cujas principais pesquisadoras são Danièle Kergoat e Helena Hirata. A partir dos estudos fomentados pelo grupo, as mulheres, antes atores invisíveis, passaram a ter consideradas suas relações sociais sexuadas, causando fecundos efeitos de renovação teórica nas Ciências Sociais (Hirata \& Kergoat, 2007; Kergoat, 2002; Hirata, 2002). Nesta linha de pesquisa, as relações sociais de sexo e a divisão sexual do trabalho tornaram-se indissociáveis, posto serem produtoras da subjetividade humana (Lombardi, 2011).

Para Hirata e Kergoat (2007, p. 599) "a divisão sexual do trabalho é a forma de divisão do trabalho social decorrente das relações sociais entre os sexos e, mais do que isso, é um fator prioritário para a sobrevivência da relação social entre os sexos". As relações sociais estabelecidas entre os sexos estão amalgamadas a fatores históricos e sociais, ou seja, é impossível isolá-las, correndo-se o risco do solipsismo, pois é "grande o perigo de se erigir um edifício conceitual perfeitamente isolado na paisagem sociológica, desconsiderando outras relações sociais que tecem com as relações sociais de sexo a trama da sociedade e impulsionam sua dinâmica" (Kergoat, 2002, p. 47). Assim, considera-se que as tensões sociais são múltiplas e nenhuma delas, isoladamente, determina a totalidade do campo que estrutura.

Condições materiais diversas impulsionaram o trabalho produtivo de mulheres no Brasil e no mundo. Estatísticas da Organização Internacional do Trabalho (OIT) revelam que havia um bilhão e duzentos milhões de mulheres trabalhando no mundo em 2007, representando uma ampliação de duzentos milhões de mulheres integrando o mercado de trabalho em uma década8 No Brasil, em 2009 havia dez milhões e quinhentas mil mulheres integrando a força de trabalho, sendo nove milhões e quinhentas mil ocupadas e um milhão desocupadas ${ }^{9}$. Apesar dos números vultosos, o acesso ao mercado não equiparou as condições de trabalho entre os sexos.

Para Hirata (2001/2002), os efeitos complexos e contraditórios da globalização afetaram desigualmente o emprego masculino e feminino nos anos 1990: por um lado, houve considerável aumento do emprego e do trabalho remunerado de mulheres em escala mundial, contudo esta participação se deu principalmente em empregos precários, vulneráveis e flexíveis; as desigualdades de salário e de condições laborais não diminuíram; e a divisão do trabalho doméstico não se modificou, permanecendo em mãos femininas. Esta opinião é compartilhada por Acker (2004). Discutindo as diferentes consequências do processo de globalização para ambos os sexos, esta autora defende que ideologias estão embutidas nas relações de gênero predominantes (1) na globalização, operando ampla separação entre a reprodução e a produção, subordinando a primeira à segunda e, consequentemente, subordinando as mulheres aos homens; (2) no importante papel da masculinidade hegemônica; e (3) no modo como as relações de gênero vêm servindo ao capital. Tal autora conclui que "a globalização teve impactos de gênero na vida de mulheres, homens e suas famílias (p. 35, tradução nossa).

7 GEDISST é a sigla de um dos principais grupos de pesquisa sobre a divisão social e sexual do trabalho, o Groupe d'Etudes sur la Division Sociale et Sexualle du Travail, fundado na década de 1970 pela socióloga francesa Danièle Kergoat. Atualmente Kergoat é pesquisadora emérita do Centre Nationale de Recherches Scientifiques - CNRS (Lombardi, 2011).

8 Informações recuperadas em 29 de junho, 2011, de: <http://www.oit.org.br/content/genero-e-raca> .

9 Informações recuperadas em 5 de outubro, 2011, de: <http://www.ibge.gov.br/home/estatistica/indicadores/trabalhoerendimento/ pme_nova/Mulher_Mercado_Trabalho_Perg_Resp.pdf >. 
Pode-se observar que as mulheres são presença majoritária no setor informal, no emprego doméstico não registrado ou na atividade por conta própria e domiciliar (Silva, 2006) e se inseriram maciçamente na atividade empreendedora (Passos et al., 2008; Bugarov et al., 2010) devido, entre outros fatores, à flexibilização do mercado de trabalho e seus reflexos nas relações sociais.

A divisão sexual do trabalho se apoia em dois princípios organizadores: o princípio de separação (há trabalhos de homens e de mulheres) e o princípio hierárquico (trabalho masculino vale mais que o feminino), constituindo subjetividades (Kergoat, 2002). A segunda forma de segregação pode configurar o que Yannoulas (2002, p. 22) denominou "teto de cristal": mecanismos articulados de discriminação encoberta e autodiscriminação que limitam as possibilidades de formação profissional ou promoção de mulheres no mercado de trabalho. Estas bases geram, principalmente, a segregação ocupacional feminina e o menor salário pago às mulheres, independente destas possuírem maior escolaridade.

Quanto à segregação, esta possui raízes históricas. As mulheres enfrentaram várias barreiras para conquistar o setor produtivo, pois o espaço público era considerado ameaçador à moralidade. Apregoava-se que o trabalho extradoméstico da mulher afrouxaria os laços e debilitaria as novas gerações, pois as crianças cresceriam soltas sem a vigilância das mães (Rago, 1997). Desta forma elas adentraram no mercado em profissões nas quais havia clara interpenetração das esferas produtiva e reprodutiva, como é o caso do Magistério e da Enfermagem (profissões que mantém perfil acentuadamente feminino).

Persistem profissões de concentração feminina, como é o caso das professoras de séries iniciais, psicólogas, secretárias, recepcionistas, enfermeiras, técnicas de enfermagem, cabeleireiras, esteticistas, faxineiras, arrumadeiras e cozinheiras (Bruschini, 2007). Para Abramo (2004, p. 225, tradução nossa), "os mecanismos de segregação ocupacional que confinam a maioria das mulheres nos segmentos menos valorizados do mercado de trabalho seguem existindo e reproduzindo-se".

O mundo ocidental permite o acesso de mulheres a quase todas as profissões e ocupações, embora estudos apontem para a persistência de desigualdades, estereótipos e preconceitos (Lombardi, 2010). Várias pesquisadoras debruçaram-se sobre o estudo da inserção de mulheres em searas tradicionalmente masculinas, tais como na indústria petroquímica (Perrelli, 2005), nas carreiras jurídicas (Barbalho, 2008), engenharias (Lombardi, 2006), em orquestras sinfônicas (Pichoneri, 2011), nas Forças Armadas Brasileiras (Lombardi, Bruschini \& Mercado, 2009), na área de vigilância patrimonial privada (Diogo, 2012) etc. Frequentemente essas pesquisas apontam discriminação, segregação ocupacional, hierarquização sexual e outros percalços a serem enfrentados pelas pioneiras que se aventuram em trabalhos predominantemente ocupados por homens. Como exemplo, a pesquisa de Cabral (2006) sobre a inserção feminina em um centro tecnológico das áreas de Engenharias e Ciências da Computação revelou que o processo de feminização desse segmento resiste à equidade de gênero: as mulheres entrevistadas revelaram que enfrentavam maiores obstáculos que seus colegas homens e tendiam a buscar superação constante por medo de perderem espaço caso não seguissem os ditames daquele universo masculino no qual trabalhavam.

O princípio hierárquico da superioridade masculina resiste até mesmo à comparação da escolarização de ambos os sexos. Segundo o IBGE, "a média de anos de estudo dos brasileiros em 2007 foi 6,9, sendo 6,7 para homens e 7,1 para as mulheres" (Lombardi, 2010, p. 36). Não obstante, considerando as variáveis sexo e escolaridade, verifica-se que elas ainda recebem menor remuneração que os homens com o mesmo grau de instrução em todas as regiões do país (Dieese, 2001). "A maior parte da distância salarial [entre os sexos] se explica pela discriminação e não por características produtivas, já que as mulheres, tendo maiores níveis educativos, teriam, por hipótese, maior rendimento ou produtividade" (Yannoulas, 2002, p. 21). Barros, Corseuil, Santos e Firpo $(2001$, p. 2) complementam que trabalhadores/as com maior educação ou experiência 
tenderiam aos melhores cargos, contudo, "no caso dos diferenciais homem-mulher, observa-se que: a) há pouca distinção de experiência; b) as mulheres são sensivelmente mais escolarizadas; e c) não obstante, os homens têm obtido melhores condições de trabalho". A manutenção das desigualdades de gênero é um dos paradoxos perpetrados pelo capitalismo: foram criadas condições para a emancipação feminina e, simultaneamente, foi acentuada a exploração das mulheres ao estabelecer uma relação aparentemente "harmônica" entre precarização e trabalho feminino.

Outro aspecto destacado entre as pesquisadoras que articulam trabalho e gênero é a frequente conciliação realizada pelas mulheres entres os espaços produtivo e reprodutivo. Atividades produtivas são aquelas que participam da formação de valor, gerando mais-valia, excedente quantitativo do trabalho social empregado na produção (Marx, 1867/1998); as reprodutivas dizem respeito àquelas atividades relacionadas à reprodução material e simbólica do núcleo familiar, geralmente não remuneradas, tais como: alimentação, cuidados com a saúde, educação, manutenção da casa etc. (Yannoulas, 2002). Assim, verifica-se que as mulheres são as principais responsáveis pelos afazeres domésticos em seus lares (Sorj, 2010; Bruschini, 2007; Araújo \& Scalon, 2005) ou por meio da venda de serviços domésticos (Silva, 2006).

Muitas pesquisadoras questionam a abordagem conceitual dualista que dicotomiza o espaço doméstico e o trabalho remunerado. Esta concepção é enfatizada, por exemplo, por Morehead (2001). Para esta autora, o tempo vivido no trabalho e em casa envolve muitas vezes uma experiência simultânea (ser/fazer mais de uma coisa ao mesmo tempo). Esta habilidade de sincronizar tempos nem sempre reflete harmonia estrutural entre trabalho e casa, mas evidencia que as mães trabalhadoras são obrigadas a dar atenção para ambos o tempo todo. Indo em uma vertente similar, Everingham (2002) propõe que a vida doméstica gera tempo social, respondendo aos ritmos biológicos e comunais bem como à lógica do relógio. Esta autora questiona pesquisas do uso do tempo que se baseiam apenas na ordem lógica temporal da vida social, pois estas são facilmente cooptadas pelos discursos da flexibilidade no trabalho. Para Everingham, o discurso lógico temporal separou os espaços público e privado, tornando inflexível para as mulheres a conciliação de afazeres, sobretudo pela multiplicidade de temporalidades e programações sociais que as mães que trabalham fora devem coordenar.

\section{Interação entre raça e gênero no mercado de trabalho: desigualdades simbólicas e materiais}

As informações fornecidas pelo Relatório Anual das Desigualdades Raciais no Brasil (2007, $2008)^{10}$, produzido pelo Laboratório de Análises Econômicas, Históricas, Sociais e Estatísticas das Relações Raciais, fornecem importante panorama da situação atual das desigualdades raciais no Brasil, revelando indicadores relacionados às vantagens dos brancos em relação aos não brancos no que diz respeito à dinâmica do mercado de trabalho. O estudo constatou que os/as brasileiros/ as brancos/as vivem em "um país" com Índice de Desenvolvimento Humano (IDH) médio equivalente à 44a melhor posição no mundo, enquanto os/as brasileiros/as negros/as vivem "em outro Brasil" onde o IDH médio é equivalente ao 104ํ lugar. Dados do IPEA ${ }^{11}$ demonstram que a entrada dos/as negros/as no mercado de trabalho ocorre mais cedo e a saída mais tarde. Além de trabalharem por mais tempo, eles/as ocupam as piores posições no mercado, estão mais expostos/ as ao trabalho sem proteção social e são mais presentes no emprego doméstico, acarretando mais desvantagens que os homens e mulheres brancos/as no recolhimento da Previdência. Há ainda

10 Informações recuperadas em 21 de janeiro, 2013, de: < http://www.laeser.ie.ufrj.br/relatorios_gerais.asp >.

11 Informações recuperadas em 21 de janeiro, 2013, de: <http://www.ipea.gov.br/sites/000/2/destaque/Pesquisa_Retrato_das_ Desigualdades.pdf $>$ 
que se comentar sobre as taxas de trabalho infantil: apesar de estas estarem decaindo, as maiores taxas se encontram entre os meninos negros.

Estudo de Soares (2000) sobre variação salarial dos/as negros/as no mercado de trabalho, com base em dados da Pesquisa Nacional por Amostra de Domicílios (PNAD) de 1996, indica que quanto mais bem posicionado o indivíduo na distribuição de renda da população negra, maior o diferencial salarial negativo em relação a um indivíduo branco. Para este autor, é evidente que a sociedade brasileira não aceita que os/as negros/as ocupem posições favoráveis na estrutura de rendimentos. Quanto mais os/as negros/as avançam economicamente, mais são discriminados. Nesse estudo, tal autor demonstra que os homens negros são discriminados no contracheque recebem algo em torno de $5 \%$ a 20\% menos que os homens brancos.

Quando comparados aos homens brancos, homens negros sofrem mais discriminação na formação e na inserção ocupacional enquanto as mulheres brancas sofrem mais discriminação na definição salarial. Já entre as mulheres negras um caleidoscópio de fatores de acesso e de segregação direta explica a distância salarial em relação aos homens brancos. O grau de desigualdade é crescente conforme se caminha para o topo da hierarquia de renda e isso prevalece para todos os grupos subordinados (Bidernam \& Guimarães, 2004).

De acordo com o Departamento Intersindical de Estatística e Estudos Socioeconômicos (Dieese, 2005, p. 2), as mulheres negras são "a síntese da dupla discriminação de gênero e raça na sociedade brasileira: mais pobres, em situações de trabalho mais precárias, com menores rendimentos e as mais altas taxas de desemprego". A tese da "dupla desvantagem" supõe que efeitos de gênero e raça são aditivos de modo que a mulher não branca sofreria a soma de preconceitos associada aos dois tipos de status subordinados (Santos, 2009).

Paixão e Gomes (2008) realizaram um estudo buscando oferecer um panorama da situação da mulher negra no mercado de trabalho a partir dos indicadores do período de 1995 a 2006 referentes à População Economicamente Ativa (PEA). Os pesquisadores constataram que, no ano de 2006, a condição assalariada com carteira assinada era mais comum entre os/as trabalhadores/ as brancos/as (36,8\%) do que entre os/as negros/as (28,5\%); entre os homens brancos $(39,8 \%)$ do que entre os negros (33\%); e entre as mulheres brancas (33\%) do que entre as negras (22\%). Já o emprego assalariado sem carteira assinada era mais comum aos homens negros $(25,2 \%)$ do que aos brancos $(17,2 \%)$. Entre as mulheres, o percentual de negras era ligeiramente superior. O emprego doméstico, por sua vez, ocupava mais mulheres do que homens e mais negras do que brancas; assim uma em cada cinco negras era doméstica $(21,8 \%)$. A probabilidade de se encontrar uma mulher branca realizando serviços domésticos era 8,9 pontos percentuais inferior que a de uma negra. $O$ trabalho para o consumo próprio era quase seis vezes mais comum para uma mulher negra $(8,1 \%)$ do que para um homem branco $(1,4 \%)$. A ocupação não remunerada era mais comum entre as mulheres que entre os homens; sendo representada por $8,7 \%$ das negras e 7,4\% das brancas.

A grande desigualdade salarial repercute em piores condições de vida. Bento (2000) aponta que uma pesquisa realizada pela Fundação Seade em 1994 informou que considerável parcela das famílias chefiadas por mulheres negras em São Paulo se encontrava em situação desfavorável $(49,8 \%)$ quando comparada com as famílias chefiadas por homens brancos (17,2\%). A renda média per capita das famílias chefiadas por mulheres negras equivalia a 1,9 salários-mínimos (a mais baixa em São Paulo), sendo que essas famílias tinham o maior percentual de crianças e adolescentes entre 10 e 17 anos que não estudavam ou trabalhavam.

Pesquisa realizada por Paixão e Gomes (2008) revela que a inserção das mulheres negras no mercado de trabalho continua nitidamente pior do que a dos demais contingentes. Essas evidências se obtêm de indicadores como posição na ocupação (75\% de trabalhadoras negras sem garantias legais e mais de 20\% ocupadas como empregadas domésticas), desocupação (a taxa de desocupação das mulheres negras eram, em 2006, mais que o dobro da taxa dos homens brancos) 
e rendimento médio (as mulheres negras recebiam um terço do rendimento médio dos homens brancos, metade do das mulheres brancas e $66 \%$ do rendimento médio dos homens negros). Tal realidade reflete o conjunto de discriminações vividas por esse contingente no seio de nossa sociedade, no qual à variável cor ou raça se somam os obstáculos advindos do sexismo e cujo resultado final parece superar o mero somatório das partes.

No Brasil, a explicação da maior vantagem de gênero do homem branco se radicaria nas características da desigualdade racial. O peso da opressão racial comum de mulheres e homens não brancos deixaria um espaço menor para a realização da assimetria causal associada ao atributo de gênero. Considerando a alta vantagem de gênero a favor dos homens, a menor penalidade de gênero ${ }^{12}$ sofrida pelas mulheres não brancas em decorrência de certa compressão social introduzida pela opressão racial, não deve obscurecer o fato de estas mulheres experimentarem uma forte desigualdade de acesso aos contextos de classe caracterizados por atribuição de prestígios e reconhecimentos distintos e que, consequentemente, suscitam rendimentos desiguais. Entre as mulheres não brancas, a desigualdade racial permanece uma barreira bem mais difícil de ser transposta do que a de gênero. Na verdade, homens e mulheres não brancos estão em clara desvantagem na ordem de classe (Santos, 2009).

Os processos de seletividade social, cujos efeitos excludentes podem ser cumulativos e influenciam no controle de "bens posicionais", operam de modo muito mais forte entre as divisões raciais. Embora a maior parte do efeito de raça seja indireta e a maior parte do efeito de gênero seja direta, isso não quer dizer que raça seja menos importante do que gênero. As divisões raciais geram consequências mais pronunciadas e excludentes, assim como têm se relevado mais difíceis de serem extintas no Brasil. Essa é a realidade das mulheres negras no mercado de trabalho, cujos processos percorridos para acessá-la, conforme bem pontua a literatura, reforçam a escassez de possibilidades intrínsecas às mulheres negras.

O acesso ao mercado de trabalho formal é realizado por meio de uma série de requisitos que, em tese, determinariam a capacidade de um sujeito assumir determinado cargo. Este discurso, que antes se concentrava na qualificação, hoje, gira em torno das competências. É necessário ter certas competências para que seja possível ocupar tal cargo. No entanto, as competências caracterizam um conceito fugaz e de difícil definição. É algo que surge para atender às demandas do próprio mercado de trabalho. Fala-se em uma capacidade transitória e contingencial, adquirida por meio de experiência, ou seja, da prática no mundo do trabalho (Santos, 2011).

Contudo, o discurso das competências, relativo a quem está apto para ocupar os postos de trabalho, sobretudo os melhores cargos e remunerações, por lançar mão de certas medidas subjetivas e contingenciais, pode favorecer práticas discriminatórias no acesso ao mercado de trabalho. Afinal, ao mesmo tempo, os processos de recrutamento para posições mais valorizadas no mercado de trabalho e nos espaços sociais operam com características dos candidatos que reforçam e legitimam a divisão hierárquica do trabalho, a imagem da empresa e do próprio posto de trabalho.

A questão da "boa aparência" assola as possibilidades de inserção e de alocação das mulheres negras no mercado de trabalho. Postos que exigem determinados atributos estéticos, escondidos

12 Quando se realiza uma análise das desigualdades de gênero dentro dos grupos raciais, percebe-se que a fenda existente entre as mulheres brancas e os homens brancos é consideravelmente maior que a que se verificada entre mulheres negras e homens negros. Uma leitura precipitada desse dado pode levar à interpretação de que as mulheres brancas sofrem mais discriminação de gênero que as mulheres negras. No entanto, é necessário considerar-se que o peso da opressão racial sobre as possibilidades de homens e mulheres negros/as dá margem a um menor efeito de gênero verificado em detrimento das mulheres negras. Ao compararmos os indicadores de homens brancos e mulheres negras, contudo, observa-se a extrema desvantagem vivida por estas últimas. Já comparando os indicadores para mulheres brancas e homens negros, percebe-se que as primeiras estão em visível vantagem. $\mathrm{O}$ que se pretende demonstrar com tais reflexões é que a interação dos fatores gênero e raça opera de forma a gerar pesos desiguais a serem suportados pelos ombros dos diferentes sujeitos, de acordo com suas inscrições raciais e de gênero (Dieese, 2005; Paixão \& Gomes, 2008; Santos, 2009). 
no discurso da "boa aparência", ocupam mais mulheres brancas e amarelas. Para as mulheres negras, seus corpos negros são marcas que as fazem estarem ausentes em algumas posições do mercado de trabalho. "Desta forma, a questão da boa aparência, exigência do mundo do trabalho para as mulheres em geral, tem significado devastador na trajetória de trabalhadoras negras, já que o modelo de boa aparência é basicamente eurocêntrico" (Bento, 2000, p. 300).

Hildegardes Vianna (1979, citado por Bento, 2000) ressalta que o cabelo crespo é o que mais incomoda no aspecto físico dos/as negros/as na medida em que esse tipo de cabelo é tido como duro, feio e requer, de algum modo, uma interferência para melhorá-lo, para mudar a sua aparência. Pode-se aqui apontar que o discurso estético da boa aparência esconde em seu bojo meandros políticos discriminatórios, pois não é cabelo ou o corpo em si que causam transtornos estéticos, mas sim a relação de dominância racial aí interposta.

Conforme reiteram os indicadores sociais, o ambiente do trabalho é um espaço adverso à diversidade. As diferenças em relação ao sujeito-padrão (homem branco) redundam em condições subalternas de inserção e tratamento. Para Soares (2000), a discriminação contra os/as negros/as se dá devido à visão historicamente constituída de qual seu lugar na sociedade: aquele/a que exerce trabalhos manuais, sem fortes requisitos de qualificação, em setores industriais pouco dinâmicos. "Se o negro ficar no lugar a ele alocado, sofrerá pouca discriminação. Mas se porventura tentar ocupar um lugar ao sol, sentirá todo o peso da discriminação sobre seus ombros" (p. 24). Tal autor conclui pela difícil realidade da população negra no mercado de trabalho, particularmente das mulheres negras. Há delimitações específicas quanto ao lugar ocupado por elas, qual seja o sem seguridade, em posições de pouco prestígio, com baixa remuneração e possibilidades escassas de ascender a cargos superiores. Seu lugar é o subalterno, o não lugar.

Diante do quadro de desigualdades debatido, cabe pontuar que aqueles que estão de alguma forma discriminados ou excluídos de contextos importantes - população negra, mulheres e, em especial, mulheres negras - não são passivos diante da adversidade. Logo, não se deve precipitar crenças que atrelem esses atores ao local da aceitação e da passividade. Com os recursos disponíveis, mesmo diante de um quadro de escassez, pode ocorrer o enfrentamento. Acreditamos que esse é um foco importante a ser dado à questão: as capacidades de resistência e de enfrentamento, que inclusive podem ser potencializadas por meio de políticas públicas coerentes.

\section{Entre o não lugar e o protagonismo}

A construção das representações sobre as minorias e o estabelecimento das relações sociais e culturais entre minorias e maiorias não são, conforme já discutido, consequência natural de traços culturais ou físicos, mas construção social circunscrita por forças de relações político-econômicas (Roso et al., 2002). Buscamos neste artigo pontuar as relações desiguais estabelecidas no mercado de trabalho, tendo como escopo analítico raça e gênero. Ambas as categorias atuam pautando padrões de segregação de forma persistente - mesmo que haja legislações antidiscriminatórias, conseguem atuar por meio de práticas camufladas. A discriminação se explicita na análise dos indicadores sociais, os quais traduzem de forma inequívoca o mercado de trabalho como ambiente particularmente hostil às diferenças e às minorias. Nessa esteira, mulheres brancas, homens negros e as mulheres negras com mais propriedade têm encontrado barreiras a serem superadas para sua inserção e justa permanência no mercado de trabalho.

Tanto a população negra quanto a mulher foram historicamente constituídos por representações marcadas pela violência simbólica e por um conjunto de exclusões. Mas, ambos (e certamente a mulher negra com mais esforço) lutaram e lutam para não serem reduzidos a essas representações. Produzir contrarrepresentações que não reduzam a objetividade às tentativas de 
lhe constituir enquanto negatividade tem sido parte da luta dos movimentos sociais dos/as negros/ as e do movimento de mulheres. É preciso manter a distinção entre a representação e o objeto, porque é na pluralidade dos processos representacionais que reside a possibilidade de manter o objeto aberto para as tentativas constantes de (re)significação que lhe são dirigidas (Jodelet, 2002). Assim, ao discutir a violência racial e de gênero - dentro e fora do contexto laboral - faz-se importante incluir como contraponto as potencialidades e as resistências que as mulheres negras vêm construindo ao longo do tempo (Oliveira, Meneghel \& Bernardes, 2009).

A resistência feminina negra é histórica. Paixão e Gomes (2008) debruçaram-se sobre a análise de testamentos deixados por mulheres negras no século XVIII buscando descrever seu padrão de posses. Foi verificado algo distinto das crenças que comumente se alimenta em relação às negras daquela época, como submissas e despossuídas. "Não encontramos tão-somente mulheres submissas ou expostas à opressão, como mucamas, violentadas sexualmente ou oprimidas pelas relações de gênero no interior das próprias senzalas" (p. 955). Essas mulheres demonstraram em seus testamentos desejos, solidariedades de gênero e reflexões sobre a escravidão. As narrativas apresentavam “... mulheres negras que conheceram a escravidão, algumas talvez na própria África, e redefiniram-na na diáspora; mais que isso, inventaram escravidão e liberdade. Reorganizaram suas vidas e de seus familiares" (p. 955). Conforme os autores apontam, "há indicações de bens que vão do dinheiro, passando por roupas e adereços, além de terras e instrumentos agrícolas para a produção de mandioca" (idem). Essa é uma visão claramente diferenciada à subordinação, dependência e passividade a que estamos acostumados associar às mulheres dessa época, principalmente às negras.

De acordo com Lazarus e Folkman (1984), há dois tipos de enfrentamento. O focado no problema é uma forma mais ativa de lidar com o elemento estressor, pois são utilizadas estratégias que vão diretamente à causa do problema. Já a evitação é um processo que envolve esforços cognitivos e comportamentais para não confrontar diretamente o elemento estressor. Considera-se que o estilo evitação pode ser benéfico no ambiente de trabalho de mulheres negras devido à necessidade de manter-se na ocupação desempenhada e, muitas vezes, por ter que conviver com as pessoas ou situações que desencadeiam o estresse. No entanto, estudos indicam que a evitação está relacionada a maiores índices de depressão e/ou outros indicadores de malefício ao bem-estar psíquico de mulheres negras diante de situações em que se percebe a discriminação racial (Barnes \& Lightsey, 2005; West, Donovan \& Roemer, 2009). O enfrentamento focado no problema, por sua vez, tem sido apontado pela literatura como benéfico às mulheres negras no ambiente de trabalho por estar atrelado a uma forma ativa de manejar a questão, de modo a deslocá-las do papel de vitimização e designá-las como protagonistas no embate à situação estressora (Bento, 1995; Ribeiro, 2008; Hall, Everett \& Hamilton-Mason, 2011; West, Donovan \& Roemer, 2009).

De forma recorrente, os estudos que enfocam os estilos de enfrentamento de mulheres negras relatam o uso de estratégias como o fortalecimento dos laços de solidariedade (com colegas, no próprio ambiente de trabalho ou não - Hall, Everett \& Hamilton-Mason, 2011; West, Donovan \& Roemer, 2009; Tokita, 2013), a formação de redes de sustentação como movimentos sociais; articulações políticas, familiares etc. (Ribeiro, 2008; Hall, Everett \& Hamilton-Mason, 2011; Martins, 2013; Prestes, 2013; Prestes \& Vasconcellos, 2013; Alvarez, 2012; Tokita, 2013) e a referência à ancestralidade (Prestes, 2013; Prestes \& Vasconcellos, 2013; Tokita, 2013). São recursos utilizados - tanto em estilos que vão direto ao problema, quanto evitando tratá-lo diretamente - sobretudo, no ambiente de trabalho, onde a discriminação racial se coloca como um problema crônico (Hall, Everett \& Hamilton-Mason, 2011).

Bento (1995) realizou um estudo sobre as formas de inserção e alocação de mulheres negras no mercado de trabalho, avaliando seus padrões de enfrentamento à discriminação. Esta pesquisadora encontrou negras que procuravam desconstruir o estereótipo da inferioridade, por 
meio do acúmulo de conhecimentos sobre seu trabalho para alcançar a excelência: "ser a melhor, a mais competente, a mais honesta do trabalho". É importante ressaltar, conforme tal autora aponta, que ser a melhor não significou apenas agir segundo as expectativas, mas também "agir conforme o esperado para chegar onde não se é esperada” (p. 487). Algumas entrevistadas procuravam manter com os brancos uma relação pontual, circunscrita ao contato formal de trabalho.

Em menor número, mas não menos significativo, Bento (1995) encontrou a resistência ativa e aberta à discriminação racial. É interessante notar que essa forma de resistência ocorreu em momentos da vida dessas mulheres negras em que a identificação racial estava bastante mobilizada. Tal autora notou que conforme aumenta a identificação racial, negras e negros tendem a dar visibilidade às práticas discriminatórias e à resistência, de modo a mobilizar os/as brancos/as e, principalmente, outros/as negros/as nas ações e resoluções.

No processo de resistir, o primeiro movimento parece ser o rompimento com o não lugar forjado por outrem. A partir disso é possível reconstruir a própria história a partir dos recursos do passado, com as ferramentas de que se dispõe. Tanto Bento (1995) quanto Oliveira, Meneghel e Bernardes (2009) notaram que falando sobre discriminação e submissão, as mulheres percebem o quanto elas lutam e passam a orgulhar-se de si mesmas e da identidade negra.

É importante ressaltar a perspicácia das mulheres negras em lidarem com os recursos disponíveis na construção de alicerces fecundos para suas famílias e comunidades. Mais que alicerçar, elas edificam pontes, reinventam liberdades e fortalecem as superações. São, como Paixão e Gomes (2008) pontuam, agentes emancipatórios vitais às suas comunidades. Justamente devido ao seu contínuo esforço de superação e às artimanhas lançadas pelas mulheres negras desde o período da escravização, conseguindo criar seus filhos e alicerçar suas comunidades, enquanto os homens negros tinham menor mobilidade dentro da ordem da sociedade de classes, que a elas foram designadas "o sustentáculo da raça", por uma escola representada por Florestan Fernandes e Octávio Ianni (Bento, 2000, p. 296).

É fato que as mulheres, principalmente as negras, devem rejeitar pela sua práxis o não lugar que lhes foi atribuído. Cabe, contudo, ponderar questões cruciais embutidas em interpretações ufanistas, como aquela proposta pelos autores apontados acima e citados por Bento (2000). Se de um lado se exalta a força e a garra dessas mulheres, em um trajeto de soberania e superação, por outro lado, deve-se lançar suspeitas sobre o demasiado entusiasmo da capacidade individual de resistência. Lutar pela emancipação feminina - negra e branca - significa, em grande parte, exigir de nossos governantes Políticas Públicas que garantam às mulheres e negros/as cidadania plena. O que se verifica, de acordo com Ribeiro (2008), é que participamos de uma sociedade que acena com avanços no que tange à garantia de direitos, mas que se mantém descompassada pela continuidade de regimes excludentes, como o racismo e o machismo. "Obtivemos avanços na agenda política? Sim, muitos! Porém, não o suficiente para destruir as mazelas deixadas pela escravidão e pela abolição inacabada" (p. 988).

Mesmo reconhecendo a garra dos/as negros/as e, em particular da mulher negra, em superar as condições de adversidade, é preciso reconhecer que nos referimos a desigualdades extremas, sendo imprescindível a ação de movimentos sociais antirracismo e Políticas Públicas de combate ao racismo e de promoção da igualdade racial e de gênero. Por meio desses mecanismos, a denúncia adquire legitimidade e passa da perspectiva individual à perspectiva dos Direitos Humanos.

No sentido objetivo de incorporar as especificidades de gênero nas Políticas Públicas e constituir condições necessárias para plena cidadania feminina, foi criada em 2003 a Secretaria Especial de Políticas para as Mulheres (SEPM) ${ }^{13}$. Em 2008 foi lançado o II Plano Nacional de Políticas para as Mulheres, buscando promover a participação igualitária, plural e multirracial

$\overline{13 \text { Informações recuperadas em } 4}$ de outubro, 2011, de <http://www.sepm.gov.br/sobre $>$. 
das mulheres na sociedade. Este documento está pautado em princípios de igualdade, respeito à diversidade, equidade, autonomia, universalidade, justiça, transparência e ao controle social. A discussão em torno do documento constitui um avanço na luta das mulheres brasileiras pela igualdade de gênero e raça.

Também se faz importante citar o Programa Pró-equidade de Gênero e Raça ${ }^{14}$, que objetiva promover a igualdade de oportunidades e de tratamento entre homens e mulheres nas organizações públicas e privadas por meio do desenvolvimento de novas concepções na gestão de pessoas e na cultura organizacional. Políticas públicas que preconizem relações igualitárias no segmento laboral contribuem de forma relevante, pois os mercados não são capazes de regular espontaneamente este tipo de desigualdade (Yannoulas, 2002).

Buscou-se com este artigo evidenciar a relevância de estudos que discorram sobre as desigualdades devidas às variáveis gênero e raça, seja no ambiente de trabalho ou em outras instâncias, de modo a visibilizar a forma com que a sociedade atrela as oportunidades de mulheres e negros/as a não lugares sociais. Pontuamos, contudo, ser de suma importância que os estudos busquem, também, enfocar a capacidade de resistência dos grupos discriminados, deslocando-os de uma perspectiva de vitimização e passividade, de modo a evidenciá-los como protagonistas de suas próprias histórias. Assim, é fundamental analisar a realidade desses grupos de maneira a não incorrer em generalizações precipitadas, isto significa assumir uma postura crítico analítica que rechace o raciocínio simplista "se, logo" que atrela de modo linear desigualdade a enfrentamento.

Para finalizar, recorremos à questão levantada por Castro (2000, p. 369): que Estado seria necessário na resolução das problemáticas do trabalho? E, vamos além: que Estado seria necessário na resolução de esferas críticas que cerceiam a vida de tantos cidadãos e cidadãs? Acreditamos ser um Estado não complacente com as desigualdades, um Estado que mobilize esforços e medidas para, de fato, incluir a todas e todos. E, enquanto o ideal não se transmuta em realidade, faz-se de suma importância as ações dos movimentos sociais bem como a realização de estudos que revelem a realidade que se presentifica para além dos gabinetes.

\section{Referências}

Abramo, L. (2004). iInserción laboral de las mujeres en América Latina: Una fuerza de trabajo secundaria? Revista de Estudos Feministas, 12(2), 224-235.

Acker, J. (2004). Globalization has had gendered impacts on the lives of women, men, and their families. Critical Sociology, $30(1), 17-41$.

Alvarez, S. E. (2012). Feminismos e antirracismo: entraves e intersecções. Entrevista com Luiza Bairros, ministra da Secretaria de Políticas de Promoção da Igualdade Racial (Seppir). Estudos Feministas, Florianópolis, 20(3), 833. 850 .

Andrew, G. R. (1998). Negros e brancos em São Paulo: (1888-1988). Bauru: Edusc.

Anjos, J. C. dos (2004). Etnia, raça e saúde: sob uma perspectiva nominalista. In S. Monteiro \& L. Sansone (Orgs.). Etnicidade na América Latina: um debate sobre raça, saúde e direitos reprodutivos (pp. 97-119). Rio de Janeiro: Editora Fiocruz.

Antunes, R. (2005). O caracol e a sua concha: ensaios sobre a nova morfologia do trabalho. São Paulo: Boitempo.

Araújo, C., \& Scalon, C. (2005). Percepções e atitudes de mulheres e homens sobre a conciliação de família e trabalho pago no Brasil. In C. Araújo \& C. Scalon (Orgs.). Gênero, família e trabalho no Brasil (pp. 15-77). Rio de Janeiro: Editora FGV.

14 Informações recuperadas em 27 de dezembro, 2013, de: <http://www.sepm.gov.br/subsecretaria-de-articulacao-institucional-eacoes-tematicas/pro-equidade $>$. 
Araújo, J. N. G. de (2008). Entre servidão e sedução do trabalhador: uma secular insistência do capital. In A. M. Mendes (Org.). Trabalho e saúde: o sujeito entre emancipação e servidão (pp. 54-68). Curitiba: Juruá

Araújo, A. M. C., Amorim, E. R. A., \& Ferreira, V. C. (2004). Os sentidos do Trabalho da Mulher no contexto da reestruturação produtiva. Anais do VIII Congresso Luso-Afro-Brasileiro de Ciências Sociais. Coimbra. Recuperado em 13 de janeiro, 2012, de <http://www.ces.uc.pt/lab2004/inscricao/pdfs/painel29/AngelaAraujo_ElaineAmorim_ VeronicaFerreira.pdf $>$.

Barbalho, R. M. (2008). A feminização da carreira jurídica: construções identitárias de advogadas e juízas no âmbito do profissionalismo. Tese de Doutorado em Sociologia. Universidade de São Carlos. Centro de Educação em Ciências Humanas. São Carlos/SP. Recuperado em 28 de agosto, 2011 < http://www.ufscar.br/profissoes/biblioteca/teses/>.

Barnes, P. W., \& Lightsey, O. R. Jr. (2005). Perceived racist discrimination, coping, stress and life satisfaction. Journal of Multicultural Counseling and Development, 33(1), 48-61.

Barros, R. P. de, Corseuil, C. H., Santos, D. D. dos, \& Firpo, S. P. (2001). Inserção no mercado de trabalho: diferenças por sexo e consequências sobre o bem-estar. Texto para discussão $n^{\circ}$ 796, IPEA.

Bento, M. A. S. (1995). A mulher negra no mercado de trabalho. Estudos Feministas, 3(2), 279-288.

Bento, M. A. S. (2000). Raça e gênero no mercado de trabalho. In M. I. B. ROCHA (Org.). Trabalho e gênero: mudanças, permanências e desafios (pp. 295-307). Campinas: ABEP, NEPO/UNICAMP e CEDEPLAR/UFMG; São Paulo: Editora 34 .

Bento, M. A. S. (2002). Os psicólogos de R.H., a igualdade e a diversidade no trabalho. In B. B. Sawaia \& M. R. Namura (Orgs.). Dialética exclusão/inclusão: reflexões metodológicas e relatos de pesquisa na perspectiva da Psicologia Social Crítica (pp. 39-54). Taubaté, SP: Cabral Editora Universitária.

Bento M. A. S., \& Carone, I. (2002). Psicologia Social do Racismo (2a ed.). São Paulo: Vozes.

Biderman, C., \& Guimarães, N. A. (2004). Na ante-sala da discriminação: o preço dos atributos de sexo e cor no Brasil (1989-1999). Estudos Feministas, 12 (2), 177-200.

Bruschini, C. (2007). Trabalho e gênero no Brasil nos últimos dez anos. Cadernos de Pesquisa, 37(132), 537-572.

Bulgarov, Y, L. M.; Camargo, D. de; Cunha, S. K. da; Meza, M. L.; Souza, R. M. B \& Tolfo, R da R. (2010). Atividade empreendedora da mulher brasileira: trabalho precário ou trabalho decente?. Psicologia Argumento, 28(63), 337-349. Recuperado em 26 de novembro, 2011 de <http:/www2.pucpr.br/reol/index.php/ PA?dd $1=3935 \& d d 99=$ view $>$.

Cabral, C. G. (2006). O conhecimento dialogicamente situado: histórias de vida, valores humanistas e consciência crítica de professoras do centro tecnológico da UFSC. Tese de Doutorado em Educação Científica e Tecnológica, Universidade Federal de Santa Catarina, Florianópolis.

Castro, M. G. (2000). Trabalho, gênero e raça. In M. I. B. Rocha (Org.). Trabalho e gênero: mudanças, permanências e desafios (pp. 367-375). Campinas: ABEP, NEPO/UNICAMP e CEDEPLAR/UFMG; São Paulo: Editora 34.

Dieese (2001). A situação do trabalho no Brasil. São Paulo: Dieese.

Dieese (2005). A mulher negra no mercado de trabalho metropolitano: inserção marcada pela dupla discriminação. Estudos e Pesquisas, ano II(14), 1-8.

Diogo, M. F. (2012) "Só tem homem, pera né, eu também quero entrar nesse lugar." Reflexões sobre a inserção de mulheres no segmento de vigilância patrimonial privada. Tese de Doutorado em Psicologia, Programa de Pós-Graduação em Psicologia, Universidade Federal de Santa Catarina, Florianópolis.

Everingham, C. (2002). Engendering Time Gender equity and discourses of workplace flexibility. Time Society, 11(2/3), 335-351.

Fávero, M. H. (2010). Psicologia do gênero. Psicobiografia, sociocultura e transformações. Curitiba: Editora da UFPR.

Fonseca, T. M. G. (2000). Gênero, subjetividade e trabalho. Petrópolis: Vozes.

Guimarães, A. S. A. (1999). Racismo e Anti-Racismo no Brasil. Rio de Janeiro: Ed. 34.

Hall, J. C., Everett, J. C. \& Hamilton-Mason, J. (2011). Black women talk about workplace stress and how they cope. Journal of Black Studies, 43(2), 207-226.

Hasenbalg, C. (1979). Discriminação e desigualdades raciais no Brasil. Rio de Janeiro: Graal.

Hirata, H. (2002). Nova divisão sexual do trabalho? Um olhar voltado para a empresa e a sociedade. São Paulo: Boitempo. 
Hirata, H. (2001/2002). Globalização e divisão sexual do trabalho. Cadernos Pagu, 17/18, 139-156.

Hirata, H. (2010). A crise mundial e o impacto da reestruturação produtiva na divisão sexual do trabalho. In A. Costa, M. B. de M. Ávila, R. Silva, V. Soares \& V. Ferreira (Orgs.). Divisão sexual do trabalho, Estado e crise do capitalismo (pp. 17-32). Recife: SOS Corpo - Instituto Feminista para a Democracia.

Hirata, H., \& Kergoat, D. (2007). Novas configurações da divisão sexual do trabalho. Cadernos de Pesquisa, 37(132), 595-609.

Jodelet, D. (2002). A alteridade como produto e processo psicossocial. In A. Arruda (Org.). Representando a alteridade (2a ed.). Petrópolis: Editora Vozes.

Kergoat, D. (2002). A relação social de sexo da reprodução das relações sociais à sua subversão. Pro-posições, 13(1), 47-59.

Lazarus, R., \& Folkman, S. (1984). Stress, appraisal and coping. New York: Springer.

Lombardi, M. R. (2006). Engenheiras brasileiras: inserção e limites de gênero no campo profissional. Cadernos de Pesquisa, 36(127), 173-202.

Lombardi, M. R, Bruschini, C., \& Mercado, C. M. (2009). As mulheres nas Forças Armadas brasileiras: a Marinha do Brasil 1980-2008. São Paulo: FCC/DPE.

Lombardi, M. R. (2010). A persistência das desigualdades de gênero no mercado de trabalho. In A. Costa, M. B. de M. Ávila, R. Silva, V. Soares \& V. Ferreira (Orgs.). Divisão sexual do trabalho, Estado e crise do capitalismo (pp. 33-56). Recife: SOS Corpo - Instituto Feminista para a Democracia.

Lombardi, M. R. (2011). Resenha: Travail et Rapports Sociaux de Sexe: Rencontres autour de Danièle Kergoat. Cadernos de Pesquisa, 41(142), 319-321.

Martins, L. L. P. (2013). Afrorresilientes: a resiliência de mulheres afrodescendentes de sucesso educacional. Dissertação de Mestrado em Educação. Universidade Federal do Piauí, Teresina. 182f.

Marx, K. (1998). O capital: crítica da economia política. Liuro 1 (16ª ed.) (R. Sant'Anna, trad.). Rio de Janeiro: Civilização Brasileira. (Originalmente publicado em 1867).

Morehead, A. (2001). Synchronizing time for work and family: preliminary insights from qualitative research with mothers. Journal of Sociology, 37 (4), 355-369.

Moscovici, S. (2000). Social representations. Explorations in Social Psychology. Cambridge: Polity Press.

Oliveira, M. L. P., Meneghel, S. N., \& Bernardes, J. S. (2009). Modos de subjetivação de mulheres negras: efeitos da discriminação racial. Psicologia $\mathfrak{F}$ Sociedade, 21(2), 266-274.

Paixão, M., \& Gomes, F. (2008). Histórias das diferenças e das desigualdades revisitadas: notas sobre gênero, escravidão, raça e pós-emancipação. Estudos Feministas, 16(3), 949-964.

Passos, C. A. K. et al. (2008). Empreendedorismo no Brasil - 2007. Curitiba: IBQP.

Perrelli, M. T. (2005). Mulheres do petróleo: sentidos atribuídos por homens e mulheres a tarefas tradicionalmente consideradas masculinas. Dissertação de Mestrado em Psicologia, Universidade Federal de Santa Catarina, Florianópolis.

Pichoneri, D. F. M. (2011). Músico de orquestra: considerações sobre trabalho e gênero. In J. H. Nunes \& R. A. de. Freitas (Orgs.). Trabalho e gênero: entre a solidariedade e a desigualdade (pp. 169-184). Goiânia: Editora da PUC Goiás.

Prestes, C. R. S. (2013). Feridas até o coração erguem-se negras guerreiras. Resiliência em mulheres negras: transmissão psíquica e pertencimentos. Dissertação de Mestrado, Instituto de Psicologia, Universidade de São Paulo, São Paulo. 175f.

Prestes, C. R. S., \& Vasconcellos, E. G. Mulheres negras: resistência e resiliência ante os efeitos psicossociais do racismo. Recuperado em 26 de março, 2014, de <http:/pambazuka.org/pt/category/features/89826>

Rago, M. (1997). Trabalho feminino e sexualidade. In M. Del Priore (Org.). A história das mulheres no Brasil (pp. 578 606). São Paulo: Contexto.

Rago, M. (2000). Epistemologia feminista, gênero e história. In J. M. Pedro \& M. P. Grossi (Orgs.). Masculino, feminino, plural: gênero na interdisciplinaridade (pp. 21-42). Florianópolis: Editora Mulheres.

Ribeiro, M. (2008). Mulheres negras: Uma trajetória de criatividade, determinação e organização. Estudos Feministas, Florianópolis, 16(3), 987-1004. 
Roso, A., Strey, M. N., Guareschi, P., \& Bueno, S. M. N. (2002). Cultura e ideologia: a mídia revelando estereótipos raciais de gênero. Psicologia E⿱ Sociedade, 14(2), 74-94.

Santos, J. A. F. (2009). A interação estrutural entre a desigualdade de raça e de gênero no Brasil. Revista Brasileira de Ciências Sociais, 24(70), 37-60.

Santos, E. F. (2011). Representações sociais de estudantes negros: Universidade e trabalho. Dissertação de Mestrado em Psicologia, Programa de Pós-Graduação em Psicologia, Universidade Federal de São Carlos/SP.

Silva, H. L. F. da (2006). Limites na construção de uma identidade política: condicionantes de gênero e de classe sobre o trabalho docente na educação infantil. Sociedade e Cultura, 9(2), 327-337.

Skidmore, T. E. (1976). Preto no branco: raça e nacionalidade no pensamento brasileiro. Rio de Janeiro: Paz e Terra.

Soares, S. S. D. (2000). O perfil da discriminação no mercado de trabalho: homens negros, mulheres brancas e mulheres negras. Brasília: Ipea.

Sorj, B. (2010). Os cuidados com a família e as desigualdades de gênero e de classe. In A. Costa, M. B. de M. Ávila, R. Silva, V. Soares \& V. Ferreira (Orgs.). Divisão sexual do trabalho: Estado e crise do capitalismo (pp. 57-66). Recife: SOS Corpo - Instituto Feminista para a Democracia.

Souza-Lobo, E. (1991). A classe operária tem dois sexos. Trabalho, dominação e resistência. São Paulo: Brasiliense.

Schucman, L. V. (2012). Entre o "encardido", o "branco" e o "branquíssimo": raça, hierarquia e poder na construção da branquitude paulistana. Tese de doutorado, Instituto de Psicologia, Universidade de São Paulo, São Paulo, SP.

Telles, E. (2003). Racismo à brasileira. Rio de Janeiro: Lumará.

Tokita, M. F. (2013) Mulheres negras. Anais do V Simpósio Internacional Lutas Sociais na América Latina, Londrina, 120. 133.

West, L. M., Donovan, R. A, \& Roemer, L. Coping with racism: What works and doesn't work for Black women? Journal of Black Psychology, 36(3), 331-349.

Yannoulas, S. C. (2002). Dossiê: políticas públicas e relações de gênero no mercado de trabalho. Brasília: CFEMEA, FIG/ CIDA.

\section{Endereço para correspondência}

bete.figueroa@gmail.com

mafediogo@gmail.com

Recebido em: 02/02/2013

liavainers@gmail.com

Revisado em: 02/04/2014

Aprovado em: 07/04/2014 